\title{
Combustion Characteristics, Performance and Emissions from a Diesel Power Generator Fuelled by B7-Ethanol Blends
}

\author{
Alex de Oliveira \\ Pontifical Catholic University of Minas Gerais, Department of Mechanical Engineering \\ Av. Dom José Gaspar, 500 - 30535-610 - Belo Horizonte - MG - Brazil \\ Tel.: +55-31-9793-5407 - Fax: +55-31-3319-4910 - E-mail: alexoem@ gmail.com
}

\section{André Marcelino de Morais}

Pontifical Catholic University of Minas Gerais, Department of Mechanical Engineering Av. Dom José Gaspar, 500 - 30535-610 - Belo Horizonte - MG - Brazil Tel.: +55-31-8788-5626 - Fax: +55-31-3319-4910 - E-mail: andre.mmor@ gmail.com

\section{Osmano Souza Valente}

Pontifical Catholic University of Minas Gerais, Department of Mechanical Engineering Av. Dom José Gaspar, 500 - 30535-610 - Belo Horizonte - MG - Brazil Tel.: +55-31-9951-5567 - Fax: +55-31-3319-4910 - E-mail: osmano.valente@ gmail.com

\section{José Ricardo Sodré*}

Pontifical Catholic University of Minas Gerais, Department of Mechanical Engineering Av. Dom José Gaspar, 500 - 30535-610 - Belo Horizonte - MG - Brazil Tel.: +55-31-3319-4911 - Fax: +55-31-3319-4910 - E-mail: ricardo@ pucminas.br

\footnotetext{
* Corresponding author
} 


\begin{abstract}
The effects of fuel blends containing 5, 10 and $15 \mathrm{wt} . \%$ of anhydrous ethanol in diesel oil with 7\% of biodiesel (B7) on performance, emissions and combustion characteristics of a diesel power generator are investigated. The engine was tested with its original configuration, with the fuel blends directly injected into the combustion chamber, and the applied load varied from 5 to $37.5 \mathrm{~kW}$. The results were compared with standard B7 operation, and showed that in in-cylinder peak pressure and heat release rate were decreased at low loads and increased at high loads with the use of ethanol. Increasing ethanol concentration caused increased ignition delay, decreased combustion duration and reduced exhaust gas temperature. The use of ethanol decreased carbon dioxide $\left(\mathrm{CO}_{2}\right)$ emissions, up to $8.6 \%$ lower than $\mathrm{B} 7$. Carbon monoxide $(\mathrm{CO})$, total hydrocarbons (THC) and oxides of nitrogen $(\mathrm{NO})$ emissions showed different behavior, depending on load and ethanol concentration.
\end{abstract}

Keywords: ethanol; diesel engine; combustion; emissions; power generation. 


\section{INTRODUCTION}

One of the main challenges faced by internal combustion engines is to operate with reduced fuel consumption and pollutant emissions [1]. For diesel engine exhaust, for instance, the emission of oxides of nitrogen $(\mathrm{NOX})$ and particulate matter $(\mathrm{PM})$ is a major pollution problem [2]. Greenhouse gas emissions from the use of fossil fuels by internal combustion engines are responsible for environmental threats, including climate change and air quality degradation. Thus, many efforts have recently been spent to

reduce those types of emissions [3]. This is done by modernizing mechanical components, using electronic fuel injection systems and emission control systems, and partially replacing fossil fuels by biofuels.

Ethanol is considered a potential substitute to diesel fuel, as it is renewable, has a high latent heat of vaporization, is an oxygenated fuel, sulfur-free and has high burning rate, with high potential to reduce $\mathrm{NO}_{\mathrm{X}}$ and $\mathrm{PM}$ emissions from diesel engines [4,5]. Brazil is a major ethanol producer, and there has been an increase in domestic production of anhydrous and hydrous ethanol [6]. The feasibility of using ethanol in diesel engines benefit companies that use diesel oil as fuel in trucks, agricultural machinery and diesel power generators, through the implementation of ethanol production plants nearby the consumption place. This can reduce the costs of transportation of diesel fuel.

The use of diesel oil-ethanol blends, ethanol fumigation, dual injection, spark ignition conversion and surface ignition are widely employed techniques to use ethanol in diesel engines [7]. Studies showed that ethanol fumigation can replace up to $50 \%$ of diesel fuel demand, dual injection up to $90 \%$, and diesel oil-ethanol blends up to $25 \%$ [3]. One of the major limitations of using diesel oil-ethanol blends in compression 
ignition engines is the low miscibility of ethanol in diesel oil for a large temperature range, due to differences in the chemical structure of these components, which may cause phase separation [8]. Lapuerta et al. [9] reported studies showing that in warm countries the solubility of pure anhydrous ethanol with diesel oil is higher. The separation may occur when the ambient temperature falls below $10^{\circ} \mathrm{C}$, with high humidity or water contamination. An evaluation of the miscibility of ethanol in diesel oil showed that the presence of water in the blend favors phase separation. The authors observed that, with increasing temperature, the blends became more stable.

Zhu et al. [4] performed experiments in a 4-cylinder, direct injection diesel engine using ethanol blended with biodiesel and $0 \%, 5 \%, 10 \%$ and $15 \%$ of anhydrous ethanol. The results showed an increase of specific fuel consumption (SFC) and thermal efficiency with the use of ethanol for all tests, compared to diesel oil. A reduction of NOX emissions was observed with increasing ethanol concentration. The effect on carbon monoxide (CO) and hydrocarbon (HC) emissions depended on ethanol concentration in the fuel blend, decreasing for the blend with $5 \%$ of ethanol. The effect of ethanol in a 4-cylinder diesel engine was also studied by Park et al. [10]. The authors used $10 \%$ and $20 \%$ of anhydrous ethanol in diesel oil-ethanol blends. The results showed reduction of $\mathrm{NOX}$ and increase of $\mathrm{CO}$ and $\mathrm{HC}$ emissions with the use of ethanol. The high latent heat of evaporation of ethanol can reduce the in-cylinder temperature and, consequently, $\mathrm{NOX}$ emissions.

Hulwan and Joshi [11] studied the use of diesel oil-ethanol-biodiesel blends in a 3-cylinder diesel engine. They reported that, due to the lower cetane number and higher latent heat of evaporation of ethanol, the blends containing this fuel increase ignition delay. The lower density and viscosity of ethanol leads to better fuel atomization and air/fuel mixture, causing a rapid burning and releasing more heat. The results showed 
increased SFC and slightly increased thermal efficiency with the increase of ethanol content in the fuel. It was noticed smoke reduction for all engine loads and $\mathrm{NOX}$ emissions decrease in low loads with the ethanol use. The authors report that several studies using ethanol-diesel oil blends show divergent results of engine performance and emissions, attributed to the different operating conditions and different engines used in each study.

Yilmaz et al. [12] performed studies using diesel oil, biodiesel and ethanol blends in a diesel engine. The experiments were performed varying ethanol concentration from $3 \%$ to $25 \%$. The results showed a small increase in engine exhaust temperature and $\mathrm{CO}$ emissions with the increase of ethanol concentration. $\mathrm{NOX}$ emissions were reduced for all loads with the increase of ethanol concentration, and unburned $\mathrm{HC}$ emissions was dependent on engine operating conditions and ethanol concentration, increasing for $25 \%$ ethanol at low loads and decreasing at high loads. Armas et al. [13] evaluated the emissions of a diesel engine using blends of $90 \%$ diesel oil and $10 \%$ ethanol. The authors explain that the effects of ethanol on $\mathrm{NO}_{\mathrm{x}}$ emissions do not follow a pattern and are dependent on engine operating conditions, among other factors. The results showed a small increase of $\mathrm{NO}_{\mathrm{x}}$ emissions with the use of ethanol, in comparison with diesel oil. $\mathrm{CO}$ emissions were reduced with the use of ethanol, especially at high loads, justified by the improvement of combustion quality through the increase of oxygen presence in the fuel. The results also showed significant reduction in PM emissions and smoke opacity, and little effect on $\mathrm{HC}$ and carbon dioxide $\left(\mathrm{CO}_{2}\right)$ emissions.

This work analyze the performance of a $44 \mathrm{~kW}$ diesel power generator fuelled by blends of diesel oil and anhydrous ethanol. Tests were performed with blends containing $0 \%, 5 \%, 10 \%$ and $15 \%$ of ethanol in diesel oil, varying engine load. The 
ethanol effects in performance, emissions and combustion characteristics are presented next.

\section{METHODOLOGY}

Experiments were carried out in a production, naturally aspirated, four-stroke, and four-cylinder stationary diesel engine. The engine geometry and injection characteristics were not changed for the tests. The fuel was directly injected by a mechanically controlled system. Table 1 shows the engine main characteristics. Figure 1 shows the main measured parameters and sensor positions. The intake air mass flow rate was measured through an orifice plate, with uncertainty of $\pm 2.3 \mathrm{~kg} / \mathrm{h}$. Temperature was measured in the fuel tank, ambient air, inlet air, orifice plate inlet, exhaust gas and cooling water using K-type thermocouples ant PT-100 sensors. The uncertainty of the measured exhaust gas temperature was $\pm 7^{\circ} \mathrm{C}$; the remaining temperatures were measured with an uncertainty of $\pm 2^{\circ} \mathrm{C}$.

The inlet air humidity was measured through a thermo-hygrometer with uncertainty of $\pm 2.5 \%$ of reading and the ambient pressure was measured through a Torricelli barometer with resolution of $\pm 1.3 \mathrm{kPa}$. A platform balance was placed under the fuel tank to measure fuel consumption, with uncertainty of $\pm 0.13 \mathrm{~kg} / \mathrm{h}$. Measurement and monitoring of the electric energy generated were made by an electric transducer, with an uncertainty of $\pm 1 \%$. Total $\mathrm{HC}$ emissions was measured by a heated flame ionization detector (HFID) with \pm 1 ppm of resolution. NOx emissions was measured by a heated chemiluminescent analyzer (HCLD) with \pm 1 ppm of resolution. $\mathrm{CO}$ and $\mathrm{CO}_{2}$ were measured by non-dispersive infrared analyzers (NDIR), with resolution of $\pm 1 \mathrm{ppm}$ and $\pm 0.01 \%$, respectively. 
A piezoelectric pressure transducer with $\pm 0.5 \%$ of resolution was used to obtain the pressure data the first engine cylinder. A trigger wheel with a magnetic sensor were used to synchronize the pressure data with the engine cycle. The system was set to obtain the pressure data at 0.1 crank angle intervals.

The tests were performed with diesel oil-ethanol blends using anhydrous ethanol (99.8\% purity) concentrations, in weight basis, of 0\% (B7E0), 5\% (B7E5), $10 \%$ (B7E10) and 15\% (B7E15). The blends were prepared using a digital balance with a resolution of $\pm 1 \mathrm{~g}$. Table 2 shows the values of density, viscosity and water content for each blend. Three tests were conducted for each load applied to the engine, varying from $0 \mathrm{~kW}$, to $37.5 \mathrm{~kW}$, at the constant engine speed of $1800 \mathrm{rev} / \mathrm{min}$. The readings at each load were performed only after the exhaust gas temperature and the coolant temperature were stabilized, to assure that the steady state condition was reached. A fuel filter assembly was used for each blend in order to prevent changes in results by contamination with the fuel used in the previous test. The load power and fuel consumption results were corrected to standard conditions according to ISO 30461:2002 standard [14].

The specific fuel consumption is defined as the fuel amount required per unit power $[15,16]$, here calculated for dual fuel operation by:

where SFC is the specific fuel consumption,

is B7 mass flow rate, is ethanol mass flow rate, QLHV,B7 is the low heating value of B7 (MJ/kg), QLHV,E is the low heating value of ethanol $(\mathrm{MJ} / \mathrm{kg})$ andis the engine output power $(\mathrm{kW})$. 
To convert the molar concentration of an exhaust gas component of interest, measured in \% or ppm, into specific mass concentration per unit of energy produced, expressed in $\mathrm{g} / \mathrm{kW} . \mathrm{h}$, the following expression is used:

where

is the component composition $(\mathrm{g} / \mathrm{kW} . \mathrm{h})$,

is the component

composition $\left(\mathrm{ppm} \times 10^{-6}\right.$ or $\left.\% \times 10^{-2}\right), \quad$ is the intake air mass flow rate $(\mathrm{kg} / \mathrm{h}), \quad$ is the gas component density $\left(\mathrm{kg} / \mathrm{m}^{3}\right)$ and is the exhaust gas density $\left(\mathrm{kg} / \mathrm{m}^{3}\right)$.

The heat release analysis allow assessing the effects of ethanol on the combustion process characteristics. The apparent net heat release rate calculated from application of the first law of thermodynamics [15] to the cylinder content is:

where is the apparent net heat release rate $\left(\mathrm{J} /{ }^{\circ} \mathrm{CA}\right)$, is the ratio of specific heats, $\mathrm{c}_{\mathrm{p}} / \mathrm{c}_{\mathrm{V}}, p$ is the cylinder pressure $(\mathrm{Pa})$, is the crank angle $\left({ }^{\circ} \mathrm{CA}\right)$ and $\mathrm{V}$ is the cylinder gas volume $\left(\mathrm{m}^{3}\right)$.

The ignition delay is given by the time interval between the start of injection and the start of combustion [14]. The start of the injection is a known fixed value, and the start of combustion was determined from the second order derivative of cylinder pressure [17]. The combustion duration was defined as the crank angle interval between 
the beginning of heat release and the accumulation of $95 \%$ of the total heat released $[2,18]$.

\section{RESULTS AND DISCUSSION}

Typical curves of average in-cylinder pressure and heat release rate for different ethanol concentrations are shown in Fig. 2, for engine load of $20 \mathrm{~kW}$. At this load, the peak pressure was higher for B7E5 (3367 kPa), followed by B7E15 (3358 kPa), B7E10 $(3350 \mathrm{kPa})$ and B7E0 $(3327 \mathrm{kPa})$. For higher loads the highest peaks of pressure and heat release rates were found as the ethanol content in the fuel was increased. The air/fuel mixture formed by the fuel blends with ethanol during the premixed phase was responsible to increase the peak pressure relative to B7E0 [19]. As the engine load increases the peak cylinder pressure is increased and occurs away from the top dead center (TDC). The net heat release rate is comprised of a premixed combustion phase, followed by a diffusive combustion phase. The maximum heat release rate shows a growth up to medium loads, but decreases with approximation of the maximum loads. For all other load conditions the trend of in-cylinder pressure curves and net heat release are similar. Zhu et al. [20] reported the same behavior.

For operation with B7E15 at the load of $32.5 \mathrm{~kW}$ the engine showed instability. The analysis of the pressure curve collected during this test showed pressure levels below those shown for other fuels and larger ignition delay, $26.8^{\circ} \mathrm{CA}$, while, for other fuels, this parameter was between $21.9^{\circ} \mathrm{CA}$ and $24.3^{\circ} \mathrm{CA}$. Park et al. [10] also reported engine instability for operation with diesel oil and ethanol blends without mechanical modifications. The authors attributed the phenomenon to increased ignition delay, and stable engine operate was achieved by delaying the fuel injection timing. The in- 
cylinder and heat release rate results here presented shows similar behavior as to those reported by Hulwan et al. [11], Zhu et al. [20], Fang et al. [21] and Mohammadi et al. [22].

Through analysis of the cylinder pressure, the ignition delay was determined, as shown by Fig. 3. Increasing ethanol concentration increased the ignition delay, justified by the lower cetane number of the ethanol blends $[10,11,20]$. The ignition delay is also influenced by engine load, in-cylinder temperature and pressure. With the increase of engine load there is a tendency of decreased ignition delay, since higher temperatures are obtained [11].The shortest ignition delay, $21.7^{\circ} \mathrm{CA}$, was found for $32.5 \mathrm{~kW}$ using B7E0, and the longest, $26.8^{\circ} \mathrm{CA}$, was obtained for $37.5 \mathrm{~kW}$ using $\mathrm{B} 7 \mathrm{E} 15$, being engine operation unstable at this condition. Due to the largest ignition delay, B7E15 fuel presented the highest peak of heat release rate, of $25.3 \mathrm{~J} /{ }^{\circ} \mathrm{CA}$ (Fig. 2).

Figure 4 shows the combustion duration as a function of engine load and fuel. There is an increase of combustion duration with increasing engine load due the longer duration of fuel injection and air/fuel mixture formation [2]. The addition of ethanol caused a decrease of the combustion duration. This can be explained by the higher heat release rate in the premixed combustion phase caused by the increased ignition delay. In addition, the higher amount of oxygen in the ethanol blends reduces the pyrolysis process and increases oxidation during combustion, reducing the combustion duration [20].

Figure 5 shows the results for the specific fuel consumption calculated by Eq.

(1). The trend of the SFC curve was not altered by the addition of ethanol. For most loads, there was an increase of SFC with increasing ethanol concentration in the blends. The differences in SFC for engine operation with ethanol is due to the lower LHV and density of the fuel blends with increasing ethanol concentration $[19,23,24]$. The highest 
differences of SFC from B7E0 occurred for the engine load of $25 \mathrm{~kW}$, increasing $5 \%$ and $8.5 \%$ when B7E5 and B7E15 were used as fuel, respectively. For B7E10 the highest increase of SFC was $6.4 \%$, in comparison with B7E0, at the load of $10 \mathrm{~kW}$.

Figure 6 shows the relationship between $\mathrm{CO}_{2}$ specific emissions and engine load. $\mathrm{CO}_{2}$ is a natural product of hydrocarbon combustion and has a tendency to increase its volume concentration with increasing fuel consumption and proximity to the stoichiometric air/fuel ratio [15]. The combustion of ethanol blends did not changed the trend of $\mathrm{CO}_{2}$ emission curves. The use of ethanol caused a reduction in specific $\mathrm{CO}_{2}$ emissions in all operating conditions. In general, the largest reductions, in comparison with B7E0, occurred in the higher loads, being in the ranges from 2.5 to $7.2 \%, 3.9$ to $6.6 \%$ and 3.6 to $8.6 \%$ for B7E5, B7E10 and B7E15, respectively. The largest reductions occurred for the loads of $27.5 \mathrm{~kW}$ (B7E5), $32.5 \mathrm{~kW}$ (B7E10) and $35 \mathrm{~kW}$ (B7E15). The decrease of the cylinder gas temperature due to the ethanol high latent heat of evaporation inhibits the oxidation of $\mathrm{CO}$, which leads to a reduction of $\mathrm{CO}_{2}$ emission $[25,26] . \mathrm{CO}_{2}$ reduction is also obtained by the use of fuels with low carbon-to-hydrogen ratio and high oxygen concentration [27-29], which is the case of the ethanol blends. He et al. [27] also reported reduced $\mathrm{CO}_{2}$ emissions with the addition of ethanol to diesel oil.

Figure 7 shows the behavior of the specific $\mathrm{CO}$ emissions for the diesel oil and ethanol blends. CO formation in engines is strongly connected with combustion quality, and tends to increases with insufficient oxygen and incomplete combustion [15]. Using B7E5 CO emissions was increased up to the engine load of $30 \mathrm{~kW}$, with a maximum of $14.7 \%$ at the load of $10 \mathrm{~kW}$, in comparison with B7E0. From $30 \mathrm{~kW}$ there is a reduction of $\mathrm{CO}$ emissions, with a maximum reduction of $17.3 \%$ at the load of $37.5 \mathrm{~kW}$. For B7E10 there was an increase in $\mathrm{CO}$ emissions between 5 and $20 \mathrm{~kW}$, reaching $21.3 \%$ at the load of $5 \mathrm{~kW}$. For the engine loads of 22.5 to $37.5 \mathrm{~kW} \mathrm{CO}$ emissions reduced with 
increasing engine load, reaching a reduction of 22.7\%. B7E15 fuel showed an increase in specific emissions of $\mathrm{CO}$ in all load range, except for the load of $35 \mathrm{~kW}$, decreasing 9.8\%. For this fuel, the highest increase in $\mathrm{CO}$ emission occurred at $5 \mathrm{~kW}$, of $38.7 \%$.

The addition of ethanol to the fuel reduces the exhaust gas temperature, due to the high latent heat of evaporation of ethanol. This results in lower $\mathrm{CO}$ oxidation, increasing the emission rate of this component [27]. On the other hand, the higher oxygen concentration in fuel-rich zones of the combustion chamber with the addition of ethanol may lead to more complete combustion and reduce $\mathrm{CO}$ formation [20,23]. The results showed that these effects are dependent on engine load and ethanol concentration in the fuel. At high loads, the reduction of $\mathrm{CO}$ may be explained by an improvement in the quality of combustion (Fig. 7). At low loads, the cooling effect caused by the high latent heat of evaporation of ethanol is more significant, and produce longer ignition delays [4]. The low combustion temperature and the ignition delay can suppress the CO oxidation process, despite the availability of oxygen [11].

B710 fuel showed the highest range of reduction in $\mathrm{CO}$ emission, indicating combustion improvement with the use of ethanol (Fig. 7). In the case of B7E15, the cooling effect of ethanol may have been dominant to increase $\mathrm{CO}$ emission. Hulwan and Joshi [11] and Huang et al. [30] also reported CO emission reduction at high loads and increase at low loads, using diesel oil-ethanol blends.

Figure 8 shows total hydrocarbons (THC) specific emissions variation with the different engine loads tested. B7E5 fuel caused an increase in specific THC emissions in comparison with B7E0 between the engine loads of $5 \mathrm{~kW}$ and $20 \mathrm{~kW}$, increasing $6.8 \%$ to $2.0 \%$, respectively. From the engine load of $22.5 \mathrm{~kW}$ THC emissions was reduced for this fuel, reaching a reduction of $12.8 \%$ at $37.5 \mathrm{~kW}$. The use of B7E10 increased THC emissions between $5 \mathrm{~kW}$, by $19.1 \%$, and $32.5 \mathrm{~kW}$, by $1.4 \%$. At the engine load of 37.5 
$\mathrm{kW}$, THC emissions were reduced by $9.8 \%$ for B7E10. B7E15 presented large reductions of THC emissions between $15 \mathrm{~kW}$, decreasing $5.6 \%$, and $35 \mathrm{~kW}$, decreasing $28.0 \%$.

The emission of unburned hydrocarbons is strongly associated to combustion quality. Among the effects of ethanol is the slower vaporization of the fuel, due to the high latent heat of vaporization, which tends to increase THC emissions [10,27]. The results showed that this effect was more significant at low and medium loads (Fig. 8). Yilmaz et al. [12] also presented results indicating an increase in THC emissions at low loads and reduction at high loads. However, at high loads, the blends with ethanol showed lower THC emissions than B7E0 (Fig. 8). Lower emissions of THC can be a consequence of higher fuel burn efficiency. When ethanol is added to the fuel, more oxygen is available in the combustion, improving the burning quality. Huang et al. [30], Shi et al. [31] and Sayin et al. [32], among other authors, showed results with reduced emissions of hydrocarbons by the use of blends of diesel oil and ethanol.

The formation of oxides of nitrogen is strongly dependent on the temperature of the gas inside the cylinder, the oxygen concentration and the residence time of the gases at high temperatures [15]. The ethanol addition to diesel oil causes several effects that act one against another to form these components. The low cetane number and the large amount of oxygen in the ethanol blends cause high peak heat release rate, as shown previously, which can increase the temperature within the cylinder. On the other hand, ethanol high latent heat of evaporation and low flame temperature tend to reduce the gas temperature within the cylinder. The behavior of the $\mathrm{NOX}$ formation is dependent on the intensity of these effects during combustion, and therefore a function of the engine operation characteristics [30]. 
Figure 9 shows $\mathrm{NOX}_{\mathrm{X}}$ specific emissions variation with engine load and fuel. In general, the fuel blends containing ethanol exhibited reduction or no variation of specific $\mathrm{NO}_{\mathrm{X}}$ emissions for all loads applied. B7E5 and B7E10 fuels presented differences within the uncertainty range, in comparison with B7E0. B7E15 fuel showed significant reductions, with maximum reduction of $10.4 \%$ at the engine load of 35.0 $\mathrm{kW}$. Among the blends tested, B7E15 contains the highest ethanol concentration, and operation with a high engine load requires a high fuel amount injected. Thus, the cooling effect of ethanol at this condition inhibited $\mathrm{NO}_{\mathrm{X}}$ formation.

\section{CONCLUSIONS}

Ethanol added to B7 increased ignition delay and reduced combustion duration. Pressure and heat release rate were reduced at lower loads and increased at medium and high loads. B7 containing $15 \%$ of ethanol increased fuel consumption up to $17.9 \%$, and reduced $\mathrm{CO}_{2}$ and $\mathrm{NO}_{\mathrm{X}}$ emissions up to $8.6 \%$ and $10.4 \%$, respectively. $\mathrm{CO}$ emission was increased for low to medium engine loads and reduced up to $22.7 \%$ at full load for B7 with $10 \%$ of ethanol. THC emissions were generally increased at low loads and reduced at high loads, with a maximum reduction of $28.0 \%$ for operation with $15 \%$ of ethanol.

\section{ACKNOWLEDGMENTS}

The authors thank CAPES, CNPq research project number 304114/2013-8, FAPEMIG research project number TEC PPM 00136-13 and VALE/FAPEMIG research project number TEC RDP 00198-10 for the financial support to this work. 


\section{REFERENCES}

[1] P. Payri, P. Olmeda, J. Martín, A. Garcia, A complete OD thermodynamic predictive model for direct injection diesel engines, Appl Energy 88 (2011) 463241.

[2] D. Hansdah, S. Murugan, Bioethanol fumigation in a DI diesel engine, Fuel 130 (2014) 324-33.

[3] Z.H. Zhang, C.S. Cheung, C.D. Yao, Influence of fumigation methanol on the combustion and particulate emissions of a diesel engine, Fuel 111 (2013) 442-8.

[4] L. Zhu, C.S. Cheung, W.G. Zhang, Z. Huang, Emissions characteristics of a diesel engine operating on biodiesel and biodiesel blended with ethanol and methanol, Sci Tot Environ 408 (2010) 914-21.

[5] R.F. Brito, C.A. Martins, Experimental analysis of a diesel engine operating in Diesel-Ethanol Dual-Fuel mode, Fuel 134 (2014) 140-50.

[6] A.L.C. Franco, M.R. Cherubin, C.C. Cerri, P.S. Pavinato, C.E.P. Cerri, J. Six, C.A. Davies, Soil carbon, nitrogen and phosphorus changes under sugarcane expansion in Brazil, Sci Tot Environ 515-516 (2015) 30-8.

[7] A. Boretti, Advantages of converting Diesel engines to run as dual fuel ethanolDiesel, Appl Therm Eng 47 (2012) 1-9.

[8] P. Kwanchareon, A. Luengnaruemitchai, S. Jai-In, Solubility of a diesel-biodieselethanol blend, its fuel properties, and its emission characteristics from diesel engine, Fuel 86 (2007) 1053-61. 
[9] M. Lapuerta, O. Armas, R. Garcia-Contreras, Stability of diesel-bioethanol blends for used in diesel engines, Fuel 86 (2007) 1351-7.

[10]S.H. Park, L.M. Youn, C.S. Lee, Influence of ethanol blends on the combustion performance and exhaust emission characteristics on a four-cylinder diesel engine at various engine loads and injection timings, Fuel 90 (2011) 748-55.

[11]D.B. Hulwan, S.V. Joshi, Performance, emission and combustion characteristic of a multicylinder DI diesel engine running on diesel-ethanol-biodiesel blends of high ethanol content, Appl Energy 88 (2011) 5042-55.

[12]N. Yilmaz, F.M. Vigil, A.B. Donaldson, T. Darabseh, Investigation of CI engine emissions in biodiesel-ethanol-diesel blends as a function of ethanol concentration, Fuel 115 (2014) 790-3.

[13]O. Armas, R. García-Contreras, A. Ramos, Pollutant emissions from New European Driving Cycle with ethanol and butanol diesel blends, Fuel Proc Technol 122 (2014) 64-71.

[14]International Organization for Standardization ISO 3046-1, Reciprocating internal combustion engines - Performance - Part 1: Declarations of power, fuel and lubricating oil consumptions, and test methods - Additional requirements for engines for general use, 2002.

[15]J.B. Heywood, Internal combustion engine fundamental, 2nd ed., McGraw-Hill, 2003.

[16]A.M. Morais, M.A.M. Justino, O.S. Valente, S.M. Hanriot, J.R. Sodré, Hydrogen impacts on performance and $\mathrm{CO}_{2}$ emissions from a diesel power generator, Int $\mathbf{J}$ Hydrogen Energy 38 (2013) 6857-64. 
[17]T. Katrasnik, F. Trenc, S.R. Opresnik, A New Criterion to Determine the Start of Combustion in Diesel Engines, Trans ASME J Eng Gas Turbine Power 128 (2006) 928-33.

[18]K. Zhang, Z. Huang, B. Liu, L. Liu, D. Jiang, Y. Ren, J. Wang, Combustion characteristics of a direct-injection natural gas engine under various fuel injection timings, Appl Therm Eng 26 (2006) 806-13.

[19]L. Pidol, B. Lecointe, L. Starck, N. Jeuland, Ethanol-biodiesel-Diesel fuel blends: Performances and emissions unconventional Diesel and advanced low temperature combustions, Fuel 93 (2012) 329-38.

[20]L. Zhu, C.S. Cheung, W.G. Zhang, Combustion, performance and emission characteristics of a DI diesel engine fueled with ethanol-biodiesel blends, Fuel 90 (2011) 1743-50.

[21]Q. Fang, J. Fang, J. Zhuang, H. Zhen, Effects of ethanol-diesel-biodiesel blends on combustion emissions in premixed low temperature combustion, Appl Therm Eng 54 (2013) 541-8.

[22]A. Mohammadi, T. Ishiyama, T. Kakuta, S. Kee, Injection strategy for clean diesel engine using ethanol blended diesel fuel, SAE Tech Paper 2005-01-1725.

[23]E.A. Ajav, B. Singh, T.K. Bhattacharya, Experimental study of some performance parameters of a constant speed stationary diesel engine using ethanol-diesel blends as fuel, Biomass Bioenergy 17 (1999) 357-65.

[24]A.C. Hansen, Q. Zhang, P.W.L. Lyne, Ethanol-diesel fuel blends - a review, Bioresource Technol 96 (2005) 277-85.

[25]Z.H. Zhang, K.S. Tsang, C.S. Cheung, T.I. Chan, C.D. Yao, Effect of fumigation methanol and ethanol on the gaseous and particulate emissions of a direct-injection diesel engine, Atmos Environ 45 (2011) 2011-8. 
[26]S. Padala, C. Woo, S. Kook, E.R. Hawkes, Ethanol Utilization in a diesel engine using dual-fuelling technology, Fuel 109 (2013) 597-607.

[27]B.Q. He, S.J. Shuai, J.X. Wang, H. He, The effect of ethanol blended diesel fuels on emissions from a diesel engine, Atmos Environ 37 (2003) 4965-71.

[28]W. Ying, Z. Longbao, W. Hewu, Diesel emission improvements by the use of oxygenated DMW/diesel blend fuels, Atmos Environ 40 (2006) 2313-20.

[29]G. Paul, A. Datta, B. Mandal, Numerical investigation of the performance and emission characteristics of a CI engine using Diesel and its blends with ethanol and Jatropha biodiesel, Int J Current Eng Technol 3 (2014) 5-9.

[30]J. Huang, Y. Wang, S. Li, A.P. Rosilly, H. Yu, H. Li, Experimental investigation on the performance and emissions of a diesel engine fuelled with ethanol-diesel blends, Appl Eng 29 (2009) 2484-90.

[31]X. Shi, X. Pang, Y. Mu, H. He, S. Shuai, J. Wang, H. Chen, R. Li, Emission reduction potential using ethanol-biodiesel-diesel fuel blend on a heavy-duty diesel engine, Atmos Environ 40 (2006) 2567-74.

[32]C. Sayin, K. Uslu, M. Canakci, Influence of injection timing on the exhaust emissions of a dual-fuel CI engine, Renew Energy 33 (2008) 1314-23. 


\section{LIST OF FIGURE CAPTIONS}

Figure 1 - Schematics of the experimental apparatus.

Figure 2 - Typical curves of in-cylinder pressure and heat release rate.

Figure 3 - Ignition delay variation with diesel oil-ethanol blends. Figure

4 - Combustion duration variation with diesel oil-ethanol blends.

Figure 5 - Specific fuel consumption variation with diesel oil-ethanol blends.

Figure $6-\mathrm{CO}_{2}$ specific emissions variation with diesel oil-ethanol blends.

Figure 7 - CO specific emissions variation with diesel oil-ethanol blends.

Figure 8 - THC specific emissions variation with diesel oil-ethanol blends.

Figure $9-\mathrm{NO}_{\mathrm{x}}$ specific emissions variation with diesel oil-ethanol blends. 


\section{LIST OF TABLE CAPTIONS}

Table 1 - Diesel engine and generator details.

Table 2 - Properties of diesel oil-ethanol blends. 
Table 1 - Diesel engine and generator details.

\begin{tabular}{lll}
\hline EQUIPMENT & PARAMETER & TYPE OR VALUE \\
\hline & Cycle & Four strokes \\
& Diesel oil injection & Direct \\
& Bore $\times$ stroke & $102 \times 120 \mathrm{~mm}$ \\
ENGINE & Number of cylinders & 4, in line \\
& Total displacement & $3.922 \mathrm{~L}$ \\
& Intake system & Naturally aspirated \\
& Rated power & $44 \mathrm{~kW}$ \\
& Number of poles & 4 \\
& Voltage & $220 \mathrm{~V}$ \\
& Number of phases & 3 \\
& Rated power & $55 \mathrm{kVA}$ \\
FENERATOR & Frequency & $60 \mathrm{~Hz}$ \\
\hline
\end{tabular}


Table 2 - Properties of diesel oil-ethanol blends.

\begin{tabular}{llllll}
\hline PROPERTY & \multicolumn{4}{c}{ FUEL } & \multirow{2}{*}{ METHOD } \\
\cline { 2 - 5 } & B7E0 & B7E5 & B7E10 & B7E15 & \\
\hline DENSITY @ 20 $\mathrm{C}\left(\mathrm{kg} / \mathrm{m}^{3}\right)$ & $842 \pm 1$ & $839 \pm 1$ & $836 \pm 1$ & $833 \pm 1$ & ASTM D4052 \\
VISCOSITY @ 40 $\mathrm{C}\left(\mathrm{mm}^{2} / \mathrm{s}\right)$ & $3.0 \pm 0.1$ & $2.6 \pm 0.1$ & $2.4 \pm 0.1$ & $2.3 \pm 0.1$ & ASTM D7042 \\
WATER CONTENT $(\mathrm{mg} / \mathrm{kg})$ & $103 \pm 2$ & $256 \pm 4$ & $357 \pm 6$ & $427 \pm 7$ & ASTM E203 \\
\hline
\end{tabular}




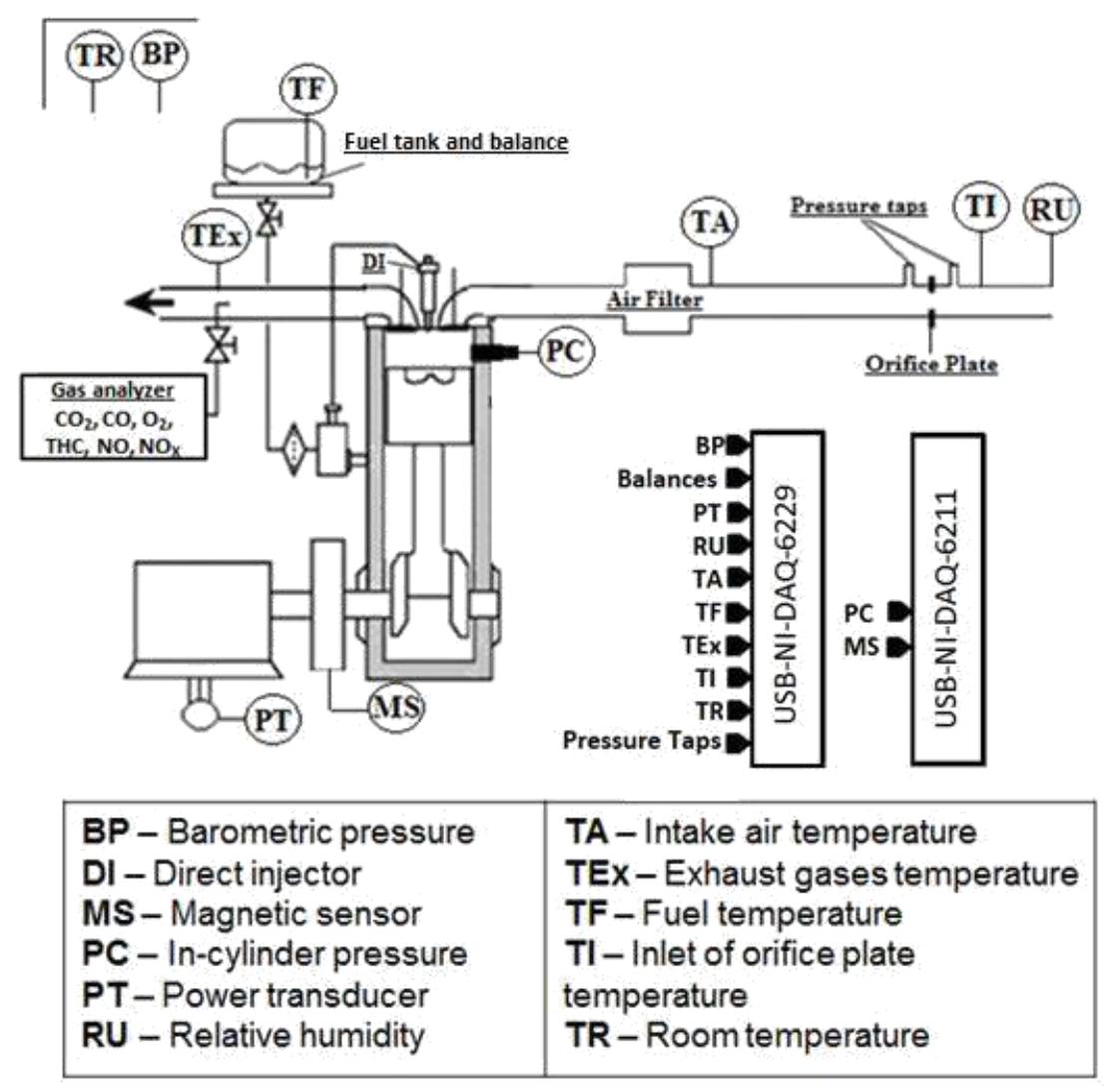

Figure 1 -Schematics of the experimental apparatus. 


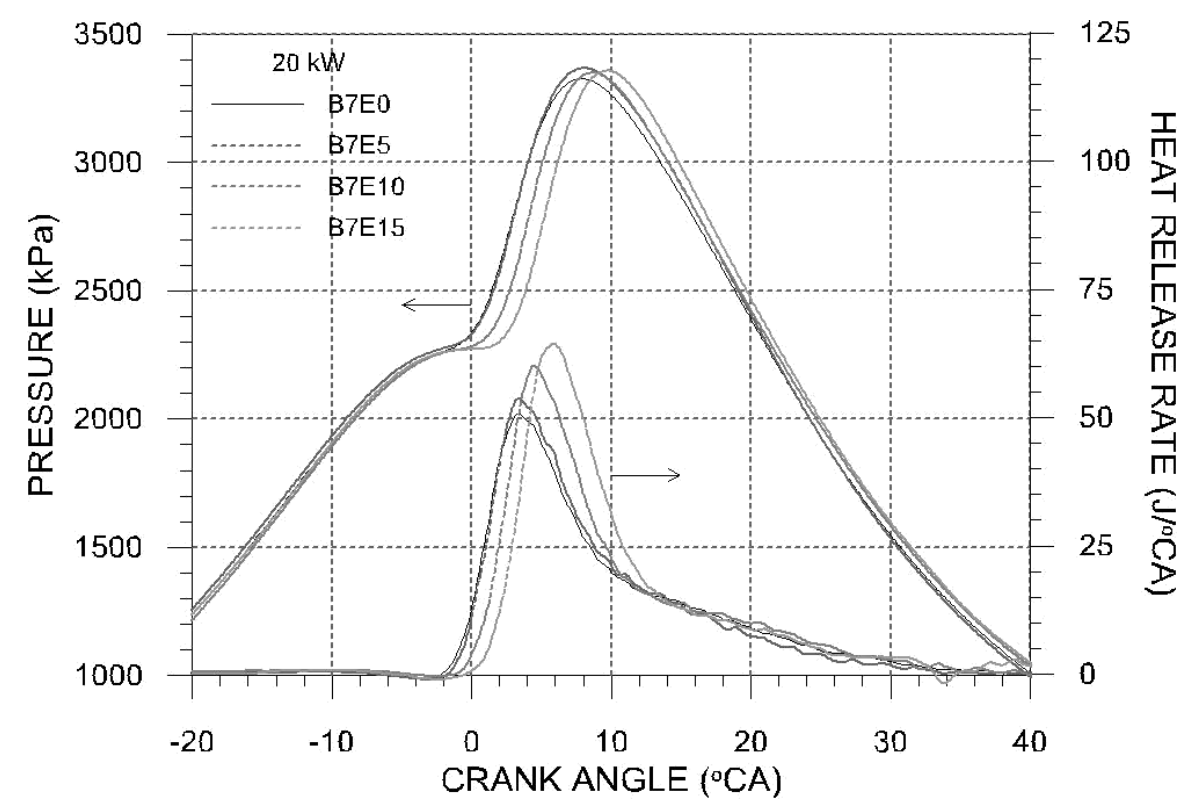

Figure 2 - Typical curves of in-cylinder pressure and heat release rate. 


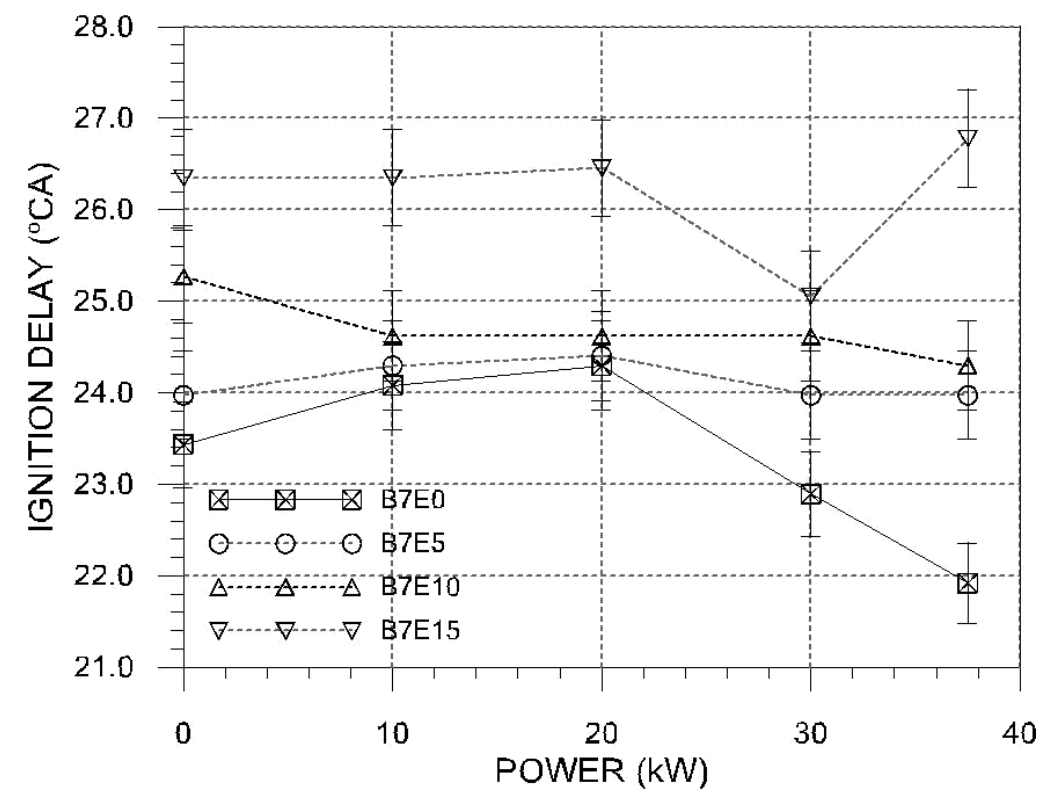

Figure 3 - Ignition delay variation with diesel oil-ethanol blends. 


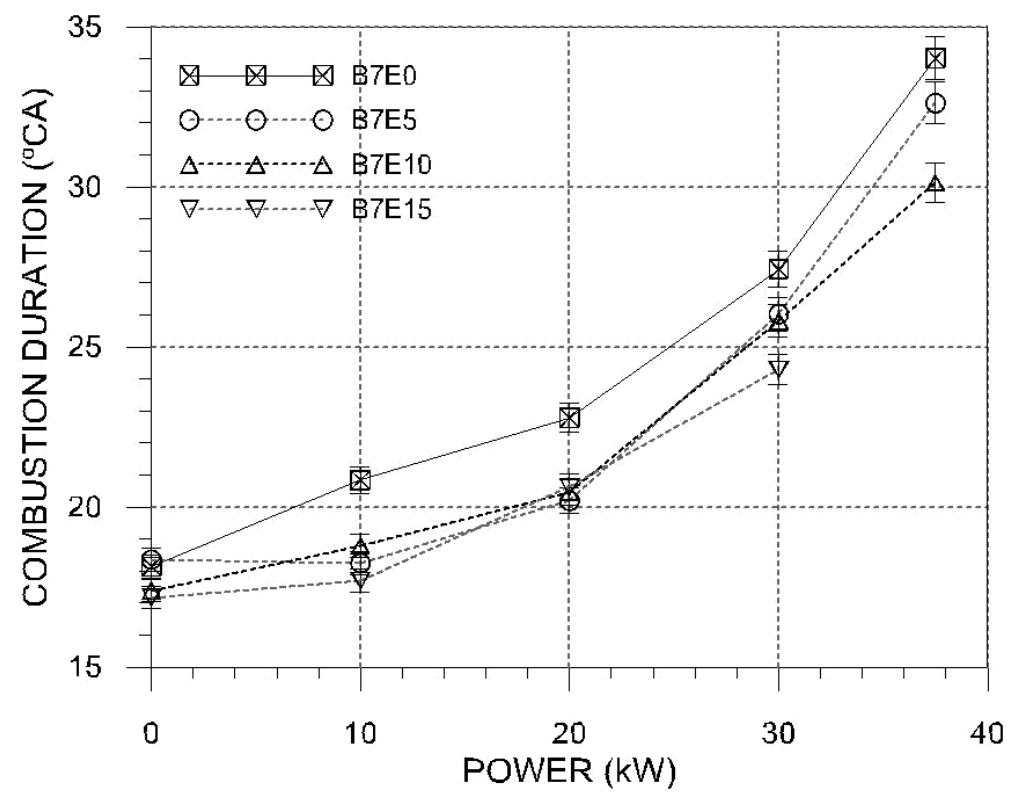

Figure 4 - Combustion duration variation with diesel oil-ethanol blends. 


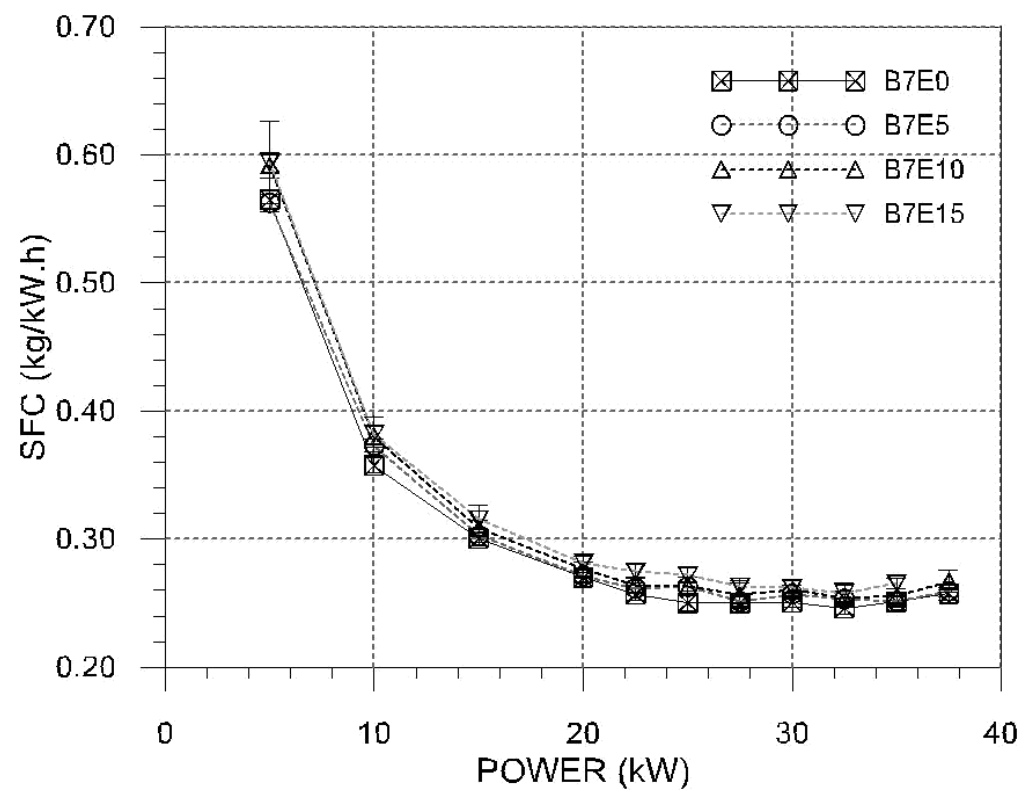

Figure 5 - Specific fuel consumption variation with diesel oil-ethanol blends. 


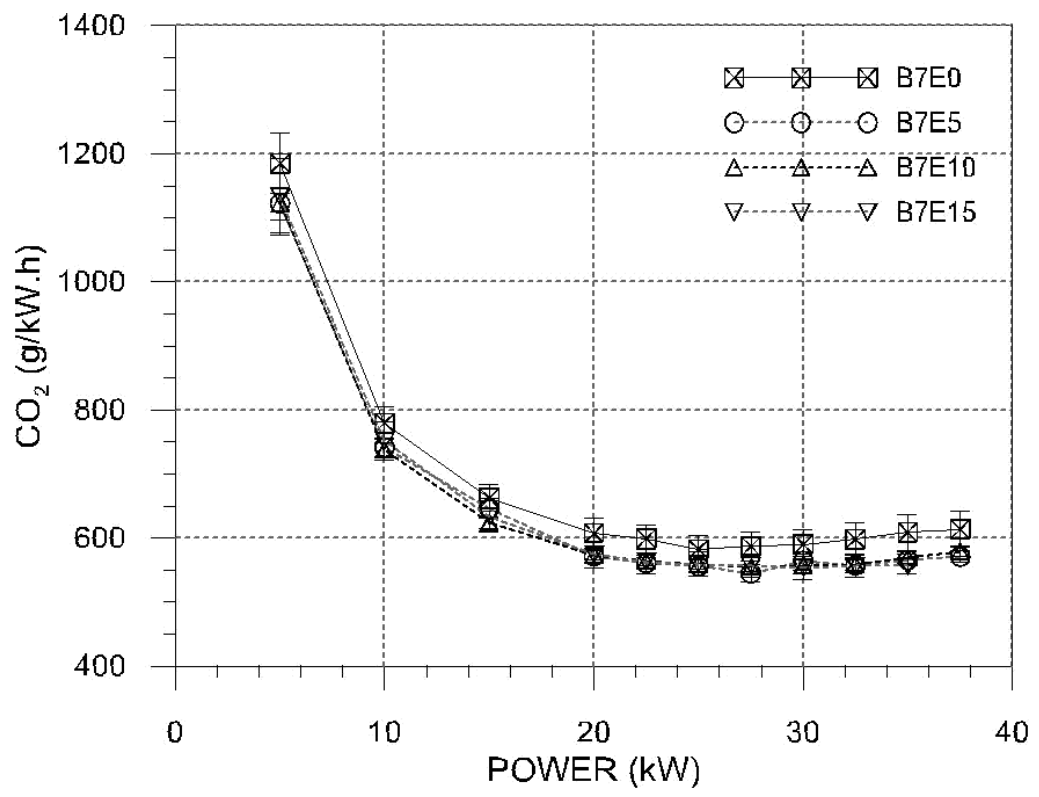

Figure $6-\mathrm{CO}_{2}$ specific emissions variation with diesel oil-ethanol blends. 


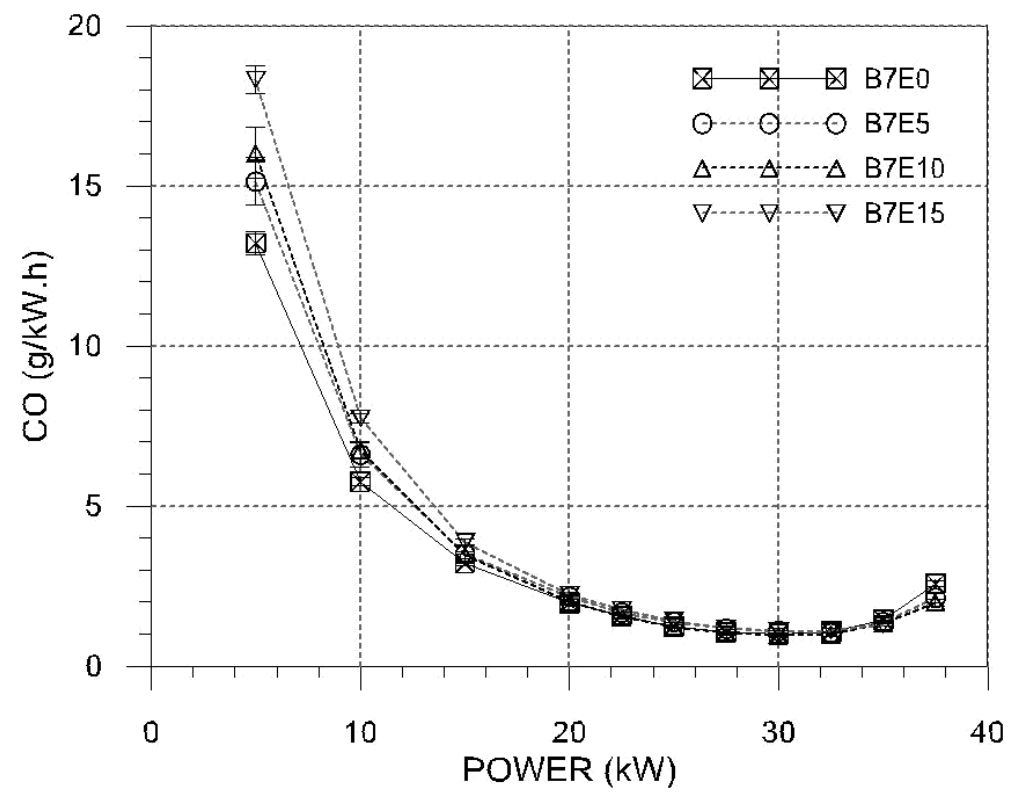

Figure 7 - CO specific emissions variation with diesel oil-ethanol blends. 


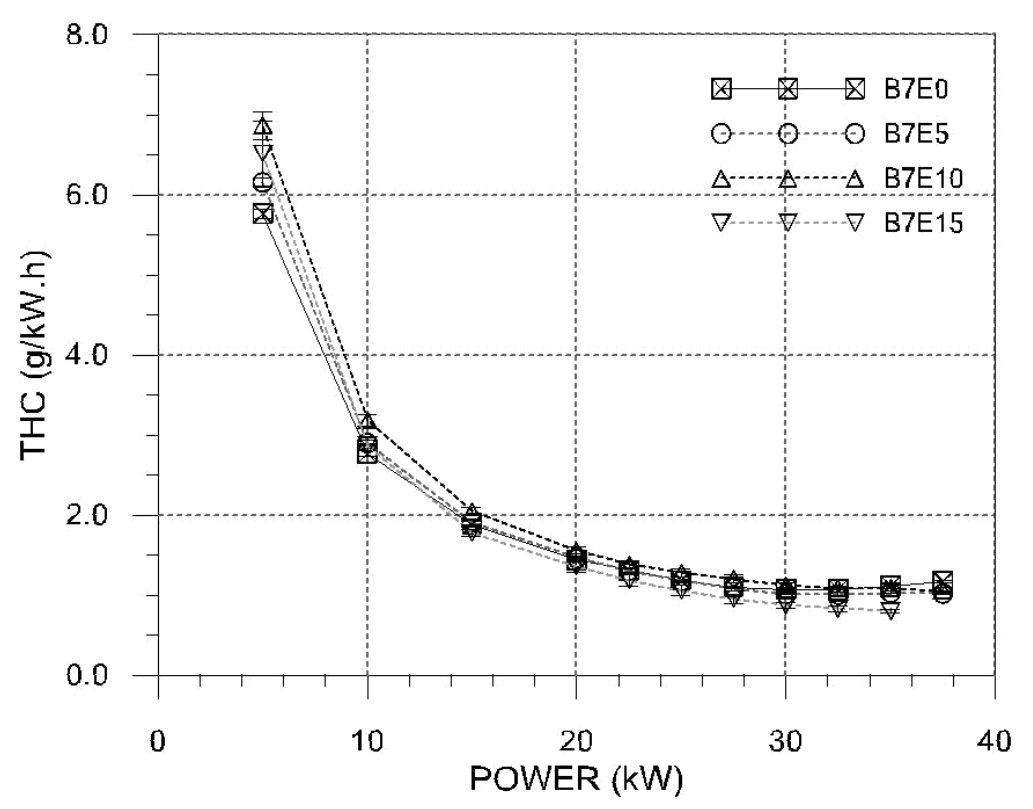

Figure 8 - THC specific emissions variation with diesel oil-ethanol blends. 


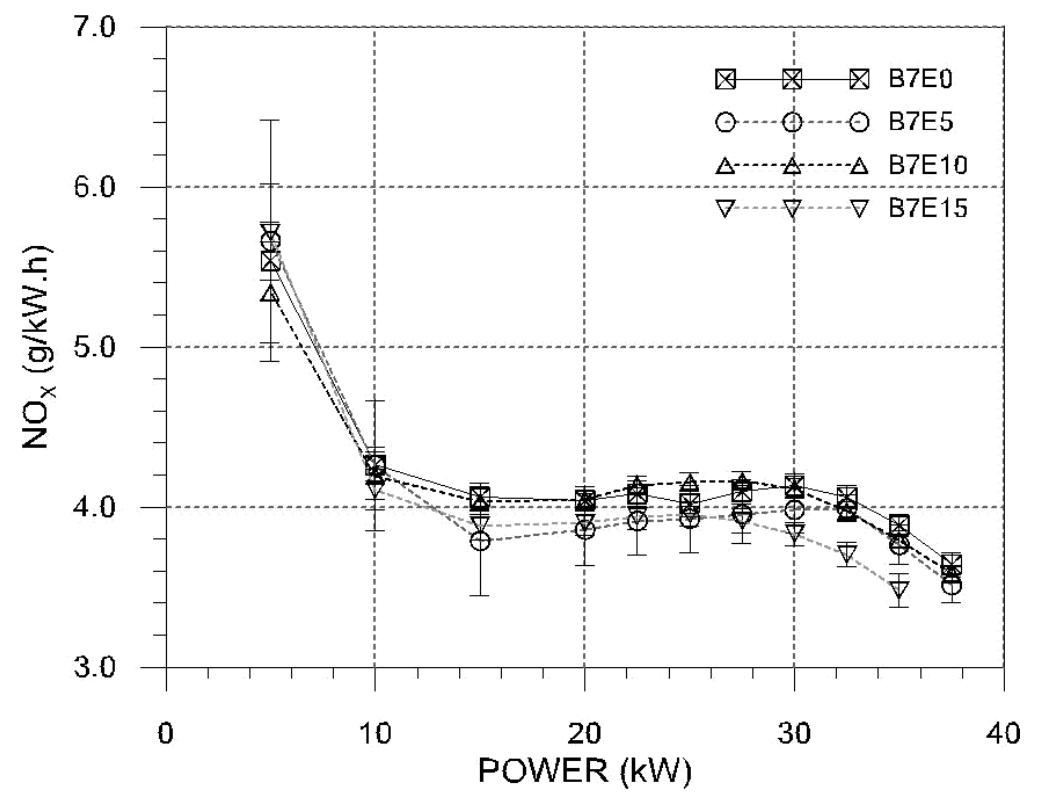

Figure 9 - NOX specific emissions variation with diesel oil-ethanol blends. 